\title{
EFICIÊNCIA ENERGÉTICA: A UTILIZAÇÃO DE COMBUSTÍVEIS NO PROCESSO DE CALCINAÇÃO
}

\author{
Tiago Scarabelli Veloso Leão \\ Egresso do Curso de Engenharia de Produção do UNIFOR-MG \\ Marcelo Carvalho Ramos \\ Professor do UNIFOR-MG \\ Tânia Aparecida de Oliveira Fonseca \\ Professora do UNIFOR-MG
}

Recebido em: 29/11/2013

Aprovado em: 24/03/2014

\begin{abstract}
RESUMO
Com a evolução histórica humana, dos tempos remotos da antiguidade à sociedade moderna, inúmeros meios de se obter energia foram desenvolvidos. Estes geradores de energia são combustíveis que possuem características únicas, como extração e transformação. Atualmente, o respeito ao meio ambiente e à natureza é de grande proporção, tornando a busca cada vez maior por fontes de energia renováveis e de baixos níveis poluentes. Entretanto, a diversidade de processos e suas necessidades energéticas ainda mantêm uma alta demanda de todos os tipos de combustíveis. Sua utilização em meios produtivos, mais especificamente em uma calcinação, objeto deste estudo, implica diretamente na realização do processo e na transformação da matéria-prima, neste caso calcário, em um produto final, a cal. Análises de seus níveis energéticos, da disponibilidade no mercado, origem e logística, adaptação ao meio, além, obviamente, dos seus custos, fornecem dados importantes para a escolha de qual é o combustível mais adequado ao processo de calcinação. O estudo conclui que a fonte energética mais adequada, levando-se em conta vantagens e desvantagens, é a lenha de eucalipto.
\end{abstract}

Palavras-chave: Eficiência energética. Combustíveis. Calcinação.

\section{ENERGY EFFICIENCY: THE USE OF FUELS IN THE PROCESS OF CALCINATION}

\begin{abstract}
With human historical evolution, the ancient times of antiquity to modern society, many ways to get energy have been developed. These power generators are fuels that have unique characteristics, such as extraction and processing. Currently respect for the environment and nature is of great extent, making the growing quest for renewable energy sources and low levels of pollutants. However the diversity of processes and their energy needs still maintain a high demand for all types of fuels. Its use in means of production, more specifically in a calcination study object, directly implies the realization of the process and the transformation of raw material, in this case limestone in a final product, lime. Analyzes of their energy levels , the market availability, origin and logistics, environmental adaptation , besides , of course ,


their costs, provide important data for the choice of which is best suited to the calcination process fuel. The study concludes that the most appropriate energy source, taking into account advantages and disadvantages is the eucalyptus firewood.

Keywords: Energy efficiency. Fuels. Calcination.

\section{INTRODUÇÃO}

De modo geral, a consciência ambiental e a sustentabilidade já se incorporaram às empresas. A necessidade de um desenvolvimento que minimize as agressões ao ambiente e à natureza é presente na metodologia corporativa. Porém, a competitividade também está mais intensa do que jamais se viu. E é a combinação entre sustentabilidade e competitividade que gera a procura ininterrupta pela eficiência produtiva e uma eficiência limpa.

Esta eficiência se caracteriza por fatores como disponibilidade, transporte, nível de poluição emitido e valores financeiros. Dependendo de cada fator, um tipo de combustível se torna mais eficiente do que outro. Além de se analisar a adaptabilidade de cada um no processo produtivo estudado.

A escolha da fonte a ser utilizada tem extrema importância e influencia diretamente nos resultados em um âmbito geral. Baixo custo de produção e mínimas taxas de emissão de poluentes dificilmente são associados, partindo, então, para a política praticada por empresa a decisão da fonte energética.

Com o foco destinado aos combustíveis regionais, este trabalho estuda e analisa individualmente os de maior demanda, como os fósseis, resíduos e subprodutos do petróleo, minerais e vegetais, como o carvão, procurando identificar as vantagens e a consequente opção mais eficiente.

A metodologia utilizada neste trabalho envolve, além da pesquisa bibliográfica, dados quantitativos do processo, relacionados com informações qualitativas do meio.

$\mathrm{O}$ atual processo produtivo de cal virgem é realizado com um alto nível de consumo de energia, então, surge a questão: qual seria a alternativa para se obter a melhor eficiência na transformação do produto?

O processo de fabricação de cal virgem é complexo devido à utilização de materiais com diversas características físicas e químicas. A importância de se conhecer o valor energético envolvido é essencial para a obtenção de um produto de alta qualidade. Por meio de uma análise energética dos possíveis combustíveis utilizados no processo produtivo, este estudo verifica a melhor alternativa em termos energéticos para a transformação da matéria- 
prima em produto final, níveis de poluentes gerados e dimensões econômicas, sem afetar a qualidade do produto.

Com os resultados obtidos por meio dos estudos dos combustíveis, verifica-se a possibilidade de melhorar a eficiência da produção de cal, por meio de uma atuação direta na alimentação do processo.

Este trabalho objetiva estudar o consumo energético no processo produtivo de cal virgem na empresa VL Cal e Transportes Ltda., situada em Córrego Fundo - MG, propondo a utilização de um combustível que forneça melhor rendimento, sem influenciar na energia despendida no processo de fabricação da cal.

\section{REFERENCIAL TEÓRICO}

Nos últimos anos, o desenvolvimento mundial é visível e aparentemente ilimitado. O maior problema oriundo desse desenvolvimento é um colapso ecológico. O progresso humano se baseia na superação de qualquer obstáculo, por intermédio de trabalho e tecnologia, todavia ao custo da degradação ambiental (CUNHA et al., 2003).

Neste contexto, surge o desenvolvimento sustentável que objetiva transformar as fontes de energias agressivas ao meio ambiente em fontes de energia limpa e reciclável.

\subsection{Desenvolvimento sustentável}

De modo geral, todas as civilizações foram fundamentadas na biomassa. O problema não seria retroceder aos modos de vida ancestrais, mas transformar o conhecimento dos povos baseados nos ecossistemas em ponto de início de uma moderna civilização de biomassa (SACHS, 2002).

Segundo Cavalcanti et al. (1994), desenvolvimento é a criação de condições tendentes à produção do ser humano em sua integridade, um processo e o seu sucesso resultante, incorporando objetivos destinados a certos fins.

O desenvolvimento mundial, tanto em aspectos financeiros como sociais, tem como fator essencial a energia. $\mathrm{O}$ consumo desta energia tem crescido em todo o mundo cerca de $2 \%$ ao ano, principalmente nos países em desenvolvimento. Como consequência, o consumo dos combustíveis fósseis aumentou, resultando em níveis maiores de poluição ambiental, tanto local, como regional e global (GOLDEMBERG, 2000). 
Goldemberg (1998) descreve que, atualmente, a maioria dos processos e equipamentos utilizados em diversos setores, como transporte, indústria e residência foi desenvolvida em tempos de abundância energética que era, inclusive, barata e em uma época que não havia muitas preocupações com os termos ambientais. Assim, a possibilidade de aumentar a produção e de se produzir energia limpa é uma alternativa para aumentar a competitividade das empresas e ainda melhorar suas imagens públicas em relação à poluição emitida.

O desenvolvimento sustentável em si ocorre quando as necessidades atuais são atendidas sem o comprometimento das necessidades de futuras gerações. Assim, o estabelecimento de medidas a serem tomadas, como a preservação da biodiversidade e dos ecossistemas, diminuição de consumo e desenvolvimento de tecnologias que utilizem fontes renováveis de energia, aumento industrial em países pouco desenvolvidos por meio de combustíveis ecológicos, é tão importante como adaptar o processo atual, baseado em fontes altamente poluidoras, em processos limpos e recicláveis (CAVALCANTI et al., 1994).

\subsection{A cal virgem}

Segundo a NBR 6471 (1998), cal virgem é o produto resultante do processo de calcinação, em que se constitui o óxido de cálcio em combinação natural com o óxido de magnésio, sendo capaz de reagir com água. Existem dois tipos de calcário: calcítico: $\mathrm{CaCO}_{3} \mathrm{e}$ Dolomítico: $\mathrm{CaMg}\left(\mathrm{CO}_{3}\right) 2$.

Calcário é o carbonato de cálcio natural que se encontra distribuído abundantemente na crosta da Terra apresentando-se em extensas e espessas camadas e em lentes intercaladas nas formações dos diversos períodos geológicos. Pode ser encontrado em todo o planeta e, no Brasil, é presente em praticamente todos os estados (ABREU, 1965).

Scipião (2004) afirma que existem oito principais produtos advindos do calcário além do cimento: brita calcária, granulado ou pedrisco de calcário, pó calcário (para correção do solo), calcário moído ou micronizado para indústria, cal virgem, cal hidratada, lajes calcárias para piso e revestimento e calcário para mármore. O mineral é encontrado em grandes proporções em Mato Grosso do Sul (32,3\%), Minas Gerais (18,44\%), Paraná (8,08\%), São Paulo $(6,45 \%)$ e Ceará $(3,6 \%)$, sendo os três primeiros responsáveis por $60 \%$ da produção de calcário bruto nacional.

A história da cal remota aos tempos da Idade da Pedra, no Período Paleolítico, até o final do Período Pliocênico. Na Pirâmide de Shersi, Tibet, foram encontradas ruínas em que o solo argiloso foi estabilizado com cal. Assim como no Egito, nas Pirâmides de Quéops e 
Quéfrem, em que havia presença de cal tanto nas juntas dos blocos de calcário e granito como na vedação das câmaras (GUIMARÃES, 2002).

Há, em todo o percurso humanístico, referências à utilização da cal. Na construção da Muralha da China, adjunto de terra argilosa, datado em 228 a.C., e em elaborações de estradas romanas na Inglaterra, em 120 d.C. A Europa, particularmente França, Inglaterra e Alemanha, países fortemente industrializados nos séculos XIX e XX, alavancaram a indústria de cal. Até o meio do século passado, ainda havia certo atraso na indústria brasileira, porém, de lá em diante, esta passou a competir em níveis de igualdade com as do resto do globo (GUIMARÃES, 1998).

No Brasil, 87\% da cal são provenientes das regiões Sudeste e Sul. Em Minas Gerais, local das principais indústrias nacionais, a produção ultrapassa 1 milhão de toneladas/ano e municípios como Sete Lagoas, Pedro Leopoldo, Arcos, Pains e Formiga merecem destaque. Entretanto, estados como Mato Grosso do Sul, Bahia, Paraná e Ceará possuem reservas de calcário e dolomitos de qualidade, descentralizando esse ramo industrial (BRASIL, 2009).

\subsection{A calcinação}

A calcinação é o ato de transformar o carbonato de cálcio, $\mathrm{CaCO}_{3}$, em óxido de cálcio, $\mathrm{CaO}$. No caso do calcário calcítico, a calcinação ocorre a temperaturas médias de $900^{\circ} \mathrm{C}$ e $1000^{\circ} \mathrm{C}$ (AURÉLIO, 2000).

Basicamente, existem quatro tipos de fornos: verticais, rotativos, horizontais e leito. $\mathrm{O}$ tipo de forno a ser utilizado depende do que se deseja obter e, obviamente, de condições financeiras. O mais difundido é o forno vertical (SCIPIÃO, 2004).

Brasil (2009) apresenta diversos tipos de fornos que são usados na produção de cal, variando de acordo com o tratamento e sofisticação tecnológica da empresa. Forno de barranco descontínuo, forno de barranco contínuo, forno vertical metálico de cuba simples, forno AZBE, forno vertical metálico de cubas múltiplas e fluxos. Ao entrar no forno, no caso do vertical AZBE, em seu topo, o calcário sofre um pré-aquecimento. Em seguida, ao entrar em zonas de temperaturas superiores, o calcário aquece e, então, calcina, quando atinge as temperaturas ideais. A última etapa é sua saída na zona de descarga, em que também resfria.

A má realização desse processo, tanto em relação à má calcinação quanto em tempo de exposição à temperatura de transformação maior do que o necessário, ocasiona um produto não adequado ou fora da especificação. 
Após a saída do forno, a cal se destina ao setor de classificação, em que é britada e destinada a silos de armazenamento que constituem peneiras separadoras, diferenciando, assim, o produto por tamanho.

Existem, ainda, processos realizados depois da cal virgem pronta, como moagem, para a obtenção de um produto extremamente fino; pulverizadores, em que a cal se torna um pó; e hidratação, que é a adição de água para se obter um aglomerante.

\subsection{O poder calorífico de cada combustível}

O poder calorífico é definido como a quantidade de energia em forma de calor liberada pela combustão de uma unidade de massa. Pode ser dividido em superior, em que a combustão é efetuada a volume constante e se forma água condensada durante a combustão, e inferior, que é a energia efetivamente disponível por unidade de massa de combustão (JARA, 1989).

A TAB. 1 apresenta o poder calorífico inferior PCI dos combustíveis, no intuito de fornecer os valores dos combustíveis citados neste estudo.

Tabela 1 - Poder Calorífico

\begin{tabular}{l|l}
\hline \multicolumn{1}{c|}{ Combustível } & PCI \\
\hline Coque & $7200 \mathrm{Kcal} / \mathrm{Kg}$ \\
\hline Gás Natural & $9065 \mathrm{Kcal} / \mathrm{m}^{3}$ \\
\hline Madeira (seca) & $4800 \mathrm{Kcal} / \mathrm{Kg}$ \\
\hline Madeira (verde) & $2500 \mathrm{Kcal} / \mathrm{Kg}$ \\
\hline Óleo combustível A & $9750 \mathrm{Kcal} / \mathrm{Kg}$ \\
\hline Óleo combustível B & $9940 \mathrm{Kcal} / \mathrm{Kg}$ \\
\hline Óleo combustível 2 A & $9550 \mathrm{Kcal} / \mathrm{Kg}$ \\
\hline Óleo combustível 2 B & $9920 \mathrm{Kcal} / \mathrm{Kg}$ \\
\hline Óleo combustível 3 A & $9500 \mathrm{Kcal} / \mathrm{Kg}$ \\
\hline Óleo combustível 3 B & $9870 \mathrm{Kcal} / \mathrm{Kg}$ \\
\hline Carvão Mineral (Cambuí/PR) Carvão & $6200 \mathrm{Kcal} / \mathrm{Kg}$ \\
\hline Mineral (Charqueadas/RS) & $3100 \mathrm{Kcal} / \mathrm{Kg}$ \\
\hline Carvão Mineral (Mina do Leão/RS) & $4200 \mathrm{Kcal} / \mathrm{Kg}$ \\
\hline Carvão Mineral (Tubarão/SC) & $4500 \mathrm{Kcal} / \mathrm{Kg}$ \\
\hline Carvão Vegetal & $7500 \mathrm{Kcal} / \mathrm{Kg}$ \\
\hline
\end{tabular}

Fonte: Adaptado de Aalborg Industries (2012). 
Aalborg Industries (2012) exemplifica as dimensões caloríficas dos combustíveis em um comparativo. Nota-se que existe uma variação entre o mesmo combustível devido a determinados fatores, como a umidade existente na madeira ou a região em que se encontra o carvão mineral, por exemplo.

Além de suas características caloríficas, deve-se atentar, também, para sua disponibilidade, facilidade e distância do transporte e o local de sua origem, além de seu valor financeiro e impacto ambiental.

\subsection{O impacto ambiental dos combustíveis}

Walisiewicz (2008) afirma que a era dos combustíveis fósseis está próxima do fim. A tendência é o aumento do preço dos derivados do petróleo, como coque, óleo combustível e até o gás natural. A exploração tornou-se uma atividade custosa, levando a ambientes extremos como o Ártico, áreas desérticas e o fundo do mar. Outro ponto negativo é o nível de poluição superior desses derivados relacionados a combustíveis alternativos, como a madeira e carvões.

Mesmo com a descoberta ainda contínua de bacias petrolíferas, como a feita no litoral brasileiro na década passada, que geram estabilidade comercial do combustível e seus derivados, o impacto causado pela sua exploração deve ser tratado com cautela e exige investimentos. Ecossistemas marinhos são delicados e o derramamento de óleo no mar gera degradação e destruição da diversidade (MARGALEF, 1993).

\subsection{A química dos combustíveis}

De acordo com Remade (2012), o carvão vegetal é obtido por meio da carbonização da lenha. Praticada em fornos de alvenaria em ciclos que podem durar dias, a carbonização da lenha pode atingir temperaturas de até $500^{\circ} \mathrm{C}$. É constituído em teor aproximado entre $65 \%$ a $80 \%$ de carbono fixo, $20 \%$ a $35 \%$ de material volátil e $1 \%$ a $3 \%$ de material inorgânico (cinzas). Como o carvão é reutilizado, o teor de carbono é maior devido a uma combustão já realizada. Outro problema é o alto índice de lenha nativa utilizada para a produção de carvão vegetal.

O coque verde de petróleo é um produto sólido, obtido a partir de craqueamento de óleos residuais pesados. Basicamente existem dois tipos principais: o esponja e o agulha. $\mathrm{O}$ primeiro corresponde a $90 \%$ da produção mundial. Como o coque é um derivado do petróleo, 
pode chegar ao teor de até $97 \%$ de carbono, o que se assemelha ao carvão e ao seu nível de poluição, mas, de acordo com a Petrobras, esse nível gira em torno de $89 \%$, tendo como constituição restante 1\% de enxofre e 10\% de material volátil (PETROBRAS, 2009).

Segundo Andrade et al. (2011), a lenha de eucalipto, na base seca, possui aproximadamente $50 \%$ de carbono de composição. Oxigênio e hidrogênio somam praticamente os outros 50\%, restando apenas mínimas concentrações de nitrogênio, cálcio, potássio, magnésio e sódio. Ao entrar no processo de combustão, muito de sua composição é perdida, pois não melhora o índice de capacidade de queima do calcário.

\section{MATERIAIS E MÉTODOS}

A metodologia utilizada neste estudo, atendendo aos objetivos de análise dos teores energéticos, eficiência e qualidade dos combustíveis disponíveis e adequados ao processo produtivo de cal virgem da empresa em questão, foi embasada em pesquisa qualitativa e quantitativa.

Segundo Flick et al. (2000), a pesquisa qualitativa se adapta ao caso estudado, sendo um espectro de métodos e técnicas, não seguindo um padrão único. Além disso, aponta a compreensão como princípio do conhecimento. Kish (1987) afirma três maneiras distintas de coleta no contexto qualitativo: observação, experimento e survey (sondagem).

$\mathrm{O}$ uso das duas abordagens, qualitativa e quantitativa, no estudo de um caso específico, como o descrito neste estudo, apresenta um resultado mais significativo e considerável. Santos Filho (2001) cita que essa complementaridade existente é fundamental e reconhecida por pesquisadores da área metodológica.

O estudo de caso foi realizado na empresa de calcinação VL Cal e Transportes Ltda., localizada na cidade de Córrego Fundo - MG.

O objeto de estudo foi a VL Cal, uma empresa 100\% nacional, instalada em um amplo espaço físico com aproximados $100.000 \mathrm{~m}^{2}$, possui três fornos de calcinação, silos de estocagem, balança rodoviária, escritório, oficina, garagem para frota própria, diversos maquinários e capacidade para estocagem de matéria prima e combustível superior a 90 dias. A empresa é certificada na norma ISO 9001:2008, desde agosto de 2010.

Dos combustíveis citados neste estudo, apenas três foram abordados com profundidade, devido à utilização deles em maior quantidade nos fornos regionais. Os três tipos de combustíveis mais utilizados no polo industrial de cal virgem da região são: carvão vegetal, coque de petróleo e lenha de eucalipto. 


\section{RESULTADOS E DISCUSSÃO}

O estudo apontou que o carvão, predominantemente vegetal, é reutilizado na indústria de cal, pois é adquirido após ser o combustível em outros ramos fabris, como siderurgias e cimenteiras. A compra de carvão é realizada em toneladas e a oferta é alta devido à grande quantidade dessas indústrias, que também o utilizam como fonte energética.

O coque de petróleo é comprado em refinarias, como a Petrobras, localizada no eixo Rio - São Paulo. A unidade de medida também é a tonelada. No Brasil, ainda possui como característica baixo teor de enxofre, o que é considerado vantagem ambiental, apesar de sua origem fóssil. A extração do petróleo é crescente e, consequentemente, a oferta de coque também aumenta.

O carvão é injetado ao processo de calcinação em associação ao coque de petróleo para se obter um aumento de rendimento e diminuição de custos. Tanto o coque quanto o carvão necessitam de tratamento específico para a introdução nos fornos, o que agrega valor e aumenta o custo dos combustíveis.

Para inserção no processo produtivo, ambos passam por moagem e secagem após serem mesclados. Essa ação gasta muita energia, porém, o baixo custo de aquisição do carvão e a alta capacidade calorífica do coque compensam essa preparação diferenciada das fontes energéticas e mantêm o custo extremamente competitivo.

A lenha de eucalipto, em grande abundância, é cultivada em milhares de hectares na região por produtores rurais. O preço praticado tem se mantido estável há anos, devido ao crescimento superior da oferta em relação à demanda.

Ao analisar quimicamente os combustíveis, foi possível identificar a capacidade de combustão e de poluição de cada um.

O GRAF. 1 demonstra que o teor de carbono desses combustíveis é diretamente proporcional à sua capacidade calorífica. Desta forma, quanto maior for a capacidade calorífica desses combustíveis, maior será a emissão de carbono, o que representa um aumento da poluição ambiental e, consequentemente, o aumento do efeito estufa, que impacta diretamente no aquecimento do planeta. 
Gráfico 1 - Carbono e PCI são diretamente proporcionais

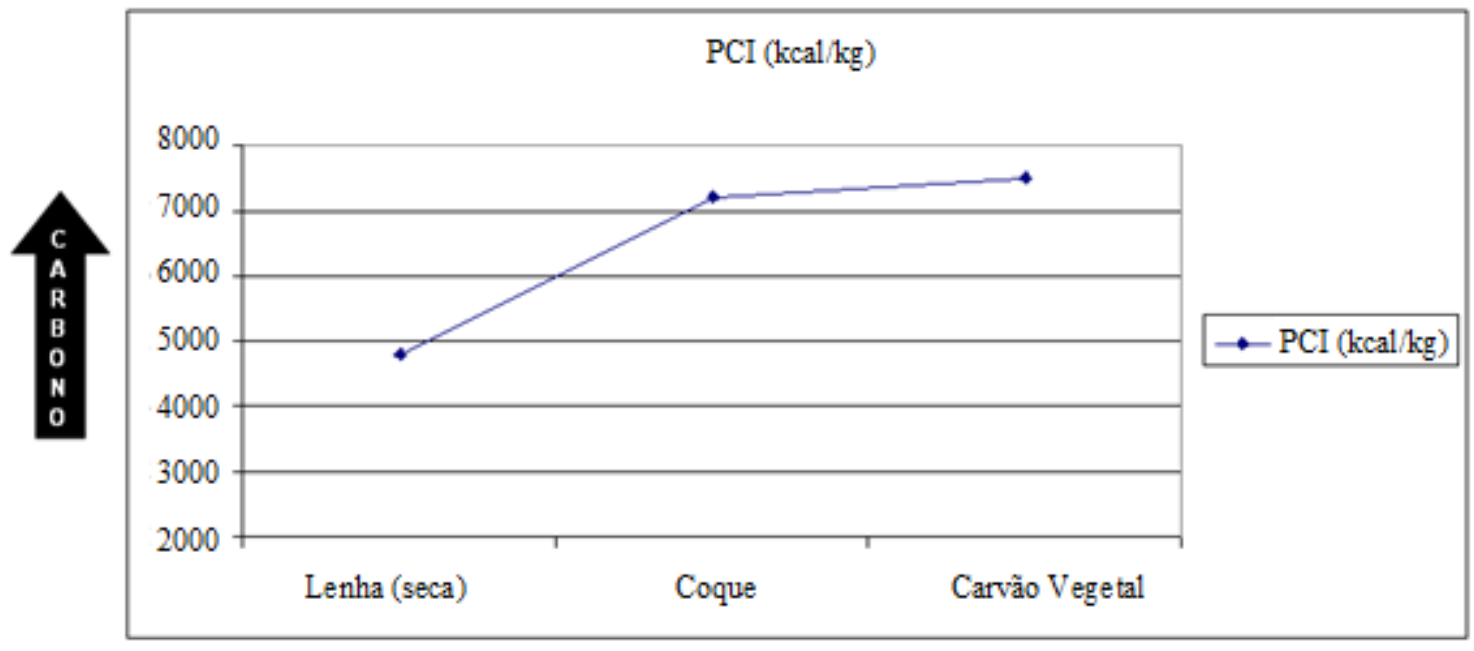

Fonte: Dados da Pesquisa, 2012

Como a madeira possui aproximadamente $50 \%$ de carbono, isto a torna a menos eficaz calorificamente em relação aos demais. Entretanto, seu nível de poluição é o menor, devido ao seu menor teor de carbono.

\subsection{Comparativo entre os combustíveis}

Para se obter resultados de eficiência das fontes energéticas, vários fatores são determinantes e seu equilíbrio implica na viabilidade dessas fontes. O comparativo mostra valores caloríficos, financeiros e disponibilidade do combustível.

A TAB. 2 apresenta uma comparação entre os preços médios dos três principais combustíveis, de acordo com a pesquisa de campo realizada.

Tabela 2 - Comparativo dos principais combustíveis

\begin{tabular}{l|c|c|c}
\hline Combustível & $\begin{array}{c}\text { Preço aproximado } \\
\text { por tonelada ou m3 }\end{array}$ & $\begin{array}{c}\text { Preço aproximado } \\
\text { por kg }\end{array}$ & $\begin{array}{c}\text { Poder calorífico por } \\
\text { unidade }\end{array}$ \\
\hline Coque de Petróleo & $\mathrm{R} \$ 400,00 / \mathrm{t}$ & $\mathrm{R} \$ 0,40 / \mathrm{kg}$ & $7200 \mathrm{kcal} / \mathrm{kg}$ \\
\hline Carvão Vegetal & $\mathrm{R} \$ 175,00 / \mathrm{t}$ & $\mathrm{R} \$ 0,175 / \mathrm{kg}$ & $7500 \mathrm{kcal} / \mathrm{kg}$ \\
\hline Lenha (seca) & $\mathrm{R} \$ 50,00 / \mathrm{m}^{3}$ & $\mathrm{R} \$ 0,125 / \mathrm{kg} *$ & $4800 \mathrm{kcal} / \mathrm{kg}$ \\
\hline
\end{tabular}

$* \mathrm{~m}^{3}$ de lenha seca $=400 \mathrm{~kg}$

Fonte: Dados da Pesquisa, 2012

Deve-se salientar que o carvão vegetal demonstrado na TAB. 2 não é o utilizado em calcinações. O produto é reutilizado, consequentemente, o poder calorífico é menor. 
Diretamente associado ao preço dos combustíveis, o rendimento é a capacidade de cada uma dessas fontes produzirem uma tonelada do produto. Então, neste ponto, deve-se levar em consideração a combinação entre o coque e carvão para se obter uma análise adequada. Essa combinação depende do tipo de processo utilizado no forno. Sua média, porém, é de $60 \%$ coque, $40 \%$ carvão, o que mantém a qualidade calorífica, por causa do coque, e um preço não tão alto, devido ao carvão.

Para a produção de um quilograma de cal, o tipo de processo, de acordo com o combustível escolhido, se há ou não uma zona de pré-aquecimento do calcário, por exemplo, interfere na necessidade aproximada de Kcal para a transformação da matéria-prima em produto. Essa quantidade pode variar entre $850 \mathrm{Kcal}$ e $1800 \mathrm{Kcal}$ por quilograma, de acordo com os dados obtidos neste trabalho. A TAB. 3 apresenta com melhor clareza a situação, baseada no valor de $850 \mathrm{kcal} / \mathrm{Kg}$.

Tabela 3 - Produção de cal por Kcal/Kg de combustível

\begin{tabular}{l|c|c}
\hline \multicolumn{1}{c|}{ Combustível } & $\begin{array}{c}\text { Poder calorífico } \\
\text { (Kcal/Kg) }\end{array}$ & $\begin{array}{c}\text { Produção de cal } \\
\text { Kg }\end{array}$ \\
\hline Coque de Petróleo & 7200 & Kcal/Kg \\
\hline Carvão Vegetal & 7500 & 8,47 \\
\hline Lenha (seca) & 4800 & 8,82 \\
\hline Fonte: Dados da Pesquisa, 2012 &
\end{tabular}

A TAB. 3 indica a produção individual dos combustíveis. Todavia, nos processos estudados, apenas a lenha seca é utilizada sem alguma combinação. Para um valor mais real de rendimento do carvão e coque, deve ser feita uma relação de $40 \%$ e $60 \%$, respectivamente, como é indicada na TAB. 4.

Tabela 4 - Produção de cal por Kcal/Kg de combustíveis combinados

\begin{tabular}{l|c|c}
\hline \multicolumn{1}{c|}{ Combustível } & $\begin{array}{c}\text { Poder calorífico } \\
\text { (Kcal/Kg) }\end{array}$ & $\begin{array}{c}\text { Produção de cal } \\
\text { Kg }\end{array}$ \\
\hline $\begin{array}{l}\text { Coque de Petróleo } \\
\text { Carvão Vegetal }\end{array}$ & 7320 & $\mathbf{K c a l} / \mathbf{~ k g}$ \\
\hline Lenha (seca) & 4800 & 8,61 \\
\hline
\end{tabular}

Fonte: Dados da Pesquisa, 2012 
Além da capacidade calorífica, a temperatura em que ocorre a transformação da matéria-prima é de extrema importância. Caso as temperaturas de $400^{\circ} \mathrm{C}$ para calcário dolomítico e $900^{\circ} \mathrm{C}$ para calcítico não sejam atingidas, o processo irá utilizar uma quantidade superior de combustível para a mesma finalidade, tornando o rendimento menor e elevando os custos.

Quando se trata de modal, ou seja, o meio de transporte de mercadorias, produtos e serviços, o utilizado para as fontes energéticas acima citadas é o rodoviário. $\mathrm{O}$ baixo custo, alta disponibilidade e facilidade de embarque e desembarque do combustível são pontos positivos. Entretanto, ao se estudar cada caso, a escolha do modal para o transporte não é uma opção. Em termos regionais, não seria possível o carregamento de madeira ou carvão em outro meio além do rodoviário. As ferrovias existentes estão totalmente voltadas para o transporte de outros produtos e a malha não é das maiores. Rios navegáveis até existem, mas o transporte não é eficaz. E devido a curta distância, para não citar custo ou disponibilidade, o modal aéreo é descartado.

Em relação ao coque, este poderia ser transportado por ferrovias de suas fontes já informadas anteriormente, eixo Rio - São Paulo, onde há refinarias maiores. Porém, o problema é o mesmo citado, a malha é significativamente inferior à rodoviária e há baixa disponibilidade.

A qualidade do produto também é um fator relevante. Combustíveis fósseis possuem mais componentes químicos do que os vegetais. Durante a combustão, há a liberação de alguns elementos, como água $(\mathrm{H} 2 \mathrm{O})$ e carbono. Todavia, há chance de contaminação do produto por outros elementos, como metais pesados, chumbo e ferro, por parte do coque, por exemplo, o que pode afetar a qualidade e criar um produto em não conformidade. No caso da madeira, essa possibilidade de contaminação não é pequena.

\subsection{Relação entre o combustível mais eficiente e o processo}

Atualmente, o sistema utilizado para a queima do combustível na empresa estudada é o tipo gasogênio, no qual a lenha de eucalipto é inserida em um recipiente e o gás da combustão é direcionado por exaustão até o calcário, realizando, assim, a transformação da matéria-prima em produto final.

Deve-se considerar que o método de combustão adotado nesses processos de calcinação é de pouca relevância já que, a longo prazo, o valor financeiro investido é irrisório. 
Mantendo a visão financeira abordada, o combustível a ser escolhido é o que deve ter peso na escolha, e não o investimento no processo a ser instalado.

A eficiência de cada combustível é influenciada por aspectos que devem ser analisados individualmente. Neste estudo, o carvão teve como principal diferencial seu baixo custo, além de uma disponibilidade satisfatória, devido ao fato de outras indústrias também utilizá-lo. Sua desvantagem é o baixo rendimento, já que é um combustível reutilizado e possui elevados índices poluidores. Neste último caso, a instalação de filtros e o destino desses resíduos retidos gerariam custos extras.

O coque de petróleo tem a capacidade calorífica mais elevada entre os três combustíveis estudados, o que pondera o maior preço, pois o seu rendimento é superior, produzindo maior qualidade de produto. Como desvantagem, assim como o carvão, eleva os índices de poluição. Sua origem fóssil também o expõe a qualquer tipo de crise petrolífera, afetando o seu abastecimento e preço.

A lenha de eucalipto é a alternativa que menos polui, é reflorestada, abundante na região e relativamente barata. Porém, é a que possui menor capacidade calorífica, ou seja, é necessária uma quantidade maior para produzir o mesmo que outros combustíveis.

No caso da empresa em estudo, o processo praticado é por intermédio da lenha, os pontos estudados tendem a mantê-lo. Mesmo com um rendimento superior, o equilíbrio financeiro e ambiental do coque associado ao carvão é menor se comparado à madeira. $\mathrm{O}$ combustível é farto na região, possui um preço estável e é caracterizado como ambientalmente correto. Além desses fatores, há ainda a possibilidade da geração de autossuficiência energética, caso seja cultivado pela própria empresa, o que pode aumentar os custos a curto prazo, entretanto estabilizar o processo a longo prazo.

\section{CONCLUSÃO}

Conclui-se que a fonte energética mais adequada, levando-se em conta vantagens e desvantagens, é a lenha de eucalipto, porém, os resultados demonstram que todos os combustíveis são viáveis. Neste caso, a própria política organizacional influenciou na escolha pela fonte energética adotada.

Questões logísticas e financeiras estudadas deram números finais em relação à eficiência de cada fonte energética, pois essas características proporcionam o abastecimento do processo de modo constante, de forma a não comprometer a qualidade do produto final. 


\section{REFERÊNCIAS}

AALBORG INDUSTRIES S.A. Poder calorífico inferior. Disponível em: <www.aalborg- industries.com.br/downloads/poder-calorifico-inf.pdf >. Acesso em: 28 maio 2012.

ABREU, S. F. Recursos minerais do Brasil: minerais não metálicos. 2. ed. Rio de Janeiro: Biblioteca Geográfica Brasileira, 1965.

ANDRADE, M. C. N. et al. Estudo comparativo da constituição nutricional da madeira e casca de espécies e clones de eucalipto visando o cultivo de shiitake em toras. Revista Árvore, Viçosa, v. 35, n. 2, 2011.

ASSOCIAÇÃO BRASILEIRA DE NORMAS TÉCNICAS. NBR 6471: Cal virgem e cal hidratada - Retirada e preparação de amostra - Procedimento. Rio de Janeiro, 1998.

AURÉLIO, B. H. F. Novo Dicionário Aurélio: século XXI. Nova Fronteira, 2000.

BRASIL. Ministério de Minas e Energia. Perfil da cal. Brasília, DF, 2009.

CAVALCANTI, C. et al. Desenvolvimento e natureza: estudos para uma sociedade sustentável. Recife: INPSO/FUNDAJ, Instituto de Pesquisas Sociais, Fundação Joaquim Nabuco, Ministério de Educação, 1994.

CUNHA, S. B. et al. A questão ambiental: diferentes abordagens. 2. ed. Rio de Janeiro: Bertrand Brasil, 2003.

FLICK, U. et al. O que é pesquisa qualitativa: uma introdução. Reinbek: Rowohlt, 2000.

GOLDEMBERG, J. Pesquisa e desenvolvimento na área de energia. São Paulo em Perspectiva, São Paulo, v. 14, n. 3, jul./set. 2000.

Energia, meio ambiente e desenvolvimento. São Paulo: Edusp, 1998.

GUIMARÃES, J. E. P. A cal: fundamentos e aplicações na engenharia civil. São Paulo: Pini, 1998.

A cal: fundamentos e aplicações na engenharia civil. 2. ed. São Paulo: Pini, 2002.

JARA, E. R. P. O poder calorífico de algumas madeiras que ocorrem no Brasil. São Paulo: Instituto de Pesquisas Tecnológicas, 1989.

KISH, L. Statistical design for research. New York: Wiley, 1987.

MARGALEF, R. Teoria dos sistemas ecológicos. Barcelona: Ediciones Universitat Barcelona, 1993. 
PETROBRAS. Coque verde de petróleo. Disponível em:

<http://www.br.com.br/wps/portal/portalconteudo/produtos/paraindustriasetermeletricas/coque verededepetroleo/> . Acesso em: 27 maio 2012.

REMADE. Carvão vegetal. Disponível em: 〈http://remade.com.br/madeira_energia.php> Acesso em: 07 nov. 2012.

SACHS, I. Caminho para o desenvolvimento sustentável. Rio de Janeiro: Garamond, 2002.

SANTOS FILHO, J. C. dos. Pesquisa quantitativa versus pesquisa qualitativa: o desafio paradigmático. 4. ed. São Paulo: Cortez, 2001.

SCIPIÃO, T. T. Nota técnica 9: panorama geral do setor mineral cearense. Fortaleza: SEPLAN, IPECE, Governo do Estado do Ceará, 2004.

WALISIEWICZ, M. Energia alternativa: solar, eólica, hidrelétrica e de biocombustíveis. São Paulo: Publifolha, 2008. 